\title{
ESTUDO DA OXIDAÇÃO PARCIAL DO ETANOL EM CATALISADORES DE Rh POR DRIFTS
}

Raquel Lima Oliveira e Fabio Barboza Passos*

Departamento de Engenharia Química e de Petróleo, Universidade Federal Fluminense, Rua Passos da Pátria, 156, 24210-240

Niterói - RJ, Brasil

Recebido em 15/4/12; aceito em 17/10/12; publicado na web em 20/2/13

\begin{abstract}
A DRIFTS STUDY OF THE PARTIAL OXIDATION OF ETHANOL ON Rh CATALYSTS. The partial oxidation of ethanol on $\gamma-\mathrm{Al}_{2} \mathrm{O}_{3}, \mathrm{CeO}_{2}, \mathrm{ZrO}_{2}$ and $\mathrm{Ce}_{\mathrm{x}} \mathrm{Zr}_{1-\mathrm{x}} \mathrm{O}_{2}$ supported rhodium catalysts was investigated by Diffuse Reflectance Infrared Fourier Transform Spectroscopy (DRIFTS). The catalysts were characterized by temperature-programmed reduction (TPR) and cyclohexane dehydrogenation. DRIFTS studies on the partial oxidation of ethanol showed that ethanol is adsorbed dissociatively, through $\mathrm{O}-\mathrm{H}$ bond breaking, with the formation of ethoxy species, followed by successive dehydrogenation to acetaldehyde and acetyl species. Further oxidation to acetate and carbonate species lead to the formation of $\mathrm{CO}, \mathrm{CH}_{4}$ and $\mathrm{H}_{2}$ by decomposition. The presence of $\mathrm{CeO}_{2}$ in the catalysts favored the oxidation steps due to its oxygen storage capacity.
\end{abstract}

Keywords: hydrogen; rhodium; ethanol.

\section{INTRODUÇÃO}

A geração de energia a partir de fontes renováveis tem sido buscada com objetivo de se diminuir a emissão de gases tóxicos para o ambiente, principalmente os emitidos pelos combustíveis fósseis. ${ }^{1} \mathrm{Em}$ especial, a produção de hidrogênio a partir de biomassa apresenta grande interesse. Quando utilizado como vetor energético em células a combustível, o hidrogênio não produz $\mathrm{CO}_{2}, \mathrm{CO}, \mathrm{SO}_{2}, \mathrm{VOC}, \mathrm{NO}_{x}$ e particulados, emitindo apenas vapor de água, que pode ser considerado não poluente, quando comparado aos compostos citados. ${ }^{2}$

A oxidação parcial de combustíveis ou óleos derivados de biomassa é uma rota alternativa bastante atrativa para produção de hidrogênio. Na oxidação parcial, os compostos oxigenados, tipicamente encontrados após o processamento da biomassa, reagem com um agente oxidante $\left(\mathrm{O}_{2}\right)$ em quantidade inferior à quantidade estequiométrica exigida para a combustão completa. A oxidação parcial é uma reação exotérmica e, portanto, menos calor deve ser fornecido ao sistema reduzindo, assim, o custo de operação. ${ }^{2}$

A oxidação parcial de compostos oxigenados ocorre de acordo com a fórmula genérica apresentada na Equação 1:

$$
\mathrm{C}_{\mathrm{n}} \mathrm{H}_{\mathrm{m}} \mathrm{O}_{\mathrm{k}}+1 / 2(\mathrm{n}-\mathrm{k}) \mathrm{O}_{2} \rightarrow \mathrm{nCO}+(\mathrm{m} / 2) \mathrm{H}_{2}
$$

As proporções da mistura de oxigênio e reagente podem ser explosivas e inflamáveis. Assim, a produção de $\mathrm{H}_{2}$ a partir da oxidação parcial tem sido estudada, principalmente em alcoóis, tais como metanol e etanol, tomando-se os devidos cuidados. ${ }^{3}$

O estudo do mecanismo de oxidação parcial de compostos oxigenados ainda é raro na literatura, quando comparado com processos de reforma a vapor. ${ }^{4}$ Como os chamados bio-óleos apresentam uma composição complexa, é interessante que se estudem moléculas representativas das funções químicas presentes nestas misturas, como os alcoóis.

O Rh é o metal mais ativo, dentre os metais nobres (Pd, Pt, Ru e Rh), para a quebra de ligações C-C envolvidas nos processos de reforma. $\mathrm{O}$ Rh também é um dos metais mais ativos utilizados para ativar a ligação $\mathrm{C}-\mathrm{H}$ e mostrou ter uma boa resistência à desativação por depósitos de carbono. A alta atividade apresentada pelo $\mathrm{Rh}$ permite utilizar um baixo teor metálico no catalisador, em torno de 0,1 a $1 \%$ em peso, o que significa uma vantagem econômica para a comercialização deste catalisador.

Neste trabalho, catalisadores de ródio suportados em $\gamma-\mathrm{Al}_{2} \mathrm{O}_{3}$, $\mathrm{CeO}_{2}, \mathrm{ZrO}_{2}$ e $\mathrm{Ce}_{\mathrm{x}} \mathrm{Zr}_{1-\mathrm{x}} \mathrm{O}_{2}$ foram caracterizados por redução à temperatura programada (TPR), desidrogenação do ciclo-hexano e as espécies superficiais formadas durante a oxidação parcial do etanol foram investigadas utilizando-se a espectroscopia no infravermelho por refletância difusa (DRIFTS).

\section{PARTE EXPERIMENTAL}

\section{Preparação dos catalisadores de ródio}

Os catalisadores foram preparados utilizando como precursor $\mathrm{Rh}\left(\mathrm{NO}_{3}\right)_{3}$, cujo teor de $\mathrm{Rh}$ foi de $1,5 \%$ pelo método de impregnação seca, onde o volume utilizado de solução impregnante é igual ao volume de poros do suporte a ser impregnado. Os materiais de partida utilizados para a obtenção dos suportes $\gamma-\mathrm{Al}_{2} \mathrm{O}_{3}, \mathrm{ZrO}_{2}$, $\mathrm{CeO}_{2}$, e $\mathrm{Ce}_{\mathrm{x}} \mathrm{Zr}_{1-\mathrm{x}} \mathrm{O}_{2}$ foram bohemita (catapal), $\mathrm{Zr}(\mathrm{OH})_{2}$ da MEL Chemicals, $\left(\mathrm{NH}_{4}\right)_{2} \mathrm{Ce}\left(\mathrm{NO}_{3}\right)_{6}$ da Aldrich e o $\mathrm{ZrO}\left(\mathrm{NO}_{3}\right)_{2}$ da Aldrich, respectivamente.

A $\gamma$-alumina e os sais precursores do $\mathrm{ZrO}_{2}$ e do $\mathrm{CeO}_{2}$ foram calcinados a $800{ }^{\circ} \mathrm{C}$ por $1 \mathrm{~h}$. Os suportes contendo $\mathrm{CeO}_{2}$ e $\mathrm{ZrO}_{2}$ em diversas composições molares $\left(\mathrm{Ce}_{0,25} \mathrm{Zr}_{0,75} \mathrm{O}_{2}, \mathrm{Ce}_{0,50} \mathrm{Zr}_{0,50} \mathrm{O}_{2}\right.$, $\mathrm{Ce}_{0,75} \mathrm{Zr}_{0,25} \mathrm{O}_{2}$ ) foram preparados pelo método de coprecipitação, utilizando-se $\mathrm{NH}_{4} \mathrm{OH}$ como agente precipitante. ${ }^{5}$

\section{Redução à temperatura programada (TPR)}

Foi utilizada uma unidade multipropósito acoplada a um espectrômetro de massas (Balzers Omnistar). O pré-tratamento da amostra (500 mg) consistiu em secagem sob fluxo de $\mathrm{He}(30 \mathrm{~mL} / \mathrm{min})$ e a análise foi realizada sob fluxo de uma mistura gasosa $5 \% \mathrm{H}_{2} / \mathrm{Ar}$ (30 $\mathrm{mL} / \mathrm{min}$ ), com uma taxa de aquecimento de $10{ }^{\circ} \mathrm{C} / \mathrm{min}$. A faixa de temperatura do TPR foi de 25 até $1000{ }^{\circ} \mathrm{C}$.

\section{Desidrogenação do ciclo-hexano}

O pré-tratamento das amostras $(10 \mathrm{mg})$ consistiu na secagem a 
$150{ }^{\circ} \mathrm{C}$, por $30 \mathrm{~min}$, sob fluxo de $\mathrm{He}(30 \mathrm{~mL} / \mathrm{min})$, seguida de redução sob fluxo de $\mathrm{H}_{2}(30 \mathrm{~mL} / \mathrm{min})$ a uma taxa de $10{ }^{\circ} \mathrm{C} / \mathrm{min}$, até $500{ }^{\circ} \mathrm{C}$. A temperatura foi elevada até $800{ }^{\circ} \mathrm{C}$ sob fluxo de He a uma taxa de $10^{\circ} \mathrm{C} / \mathrm{min}$. A alimentação ao reator foi obtida pelo arraste do ciclo-hexano pelo hidrogênio num saturador mantido à temperatura de 12 ${ }^{\circ} \mathrm{C}\left(\mathrm{pH}_{2} / \mathrm{pC}_{6} \mathrm{H}_{12}=13,2\right)$. A vazão total da corrente gasosa de alimentação foi de $100 \mathrm{~mL} / \mathrm{min}$. Os produtos da reação foram analisados utilizando-se um cromatógrafo a gás Hewlett Packard 5890 série II com uma coluna capilar HP-Innowax (polietileno glicol).

\section{Espectroscopia no infravermelho por refletância difusa (DRIFTS)}

Espectros de infravermelho in situ foram realizados com um equipamento Vértex 70 da Brucker, equipado com um detector de nitrogênio líquido LN-MCT. Foi usado um acessório de refletância difusa (Harrick) contendo uma câmara de reação (HVC-DRP-4, Harrick), que possui janelas de ZnSe, para o monitoramento in situ da reação de oxidação parcial do etanol.

Antes de cada experimento de oxidação parcial do etanol no DRIFTS, as amostras foram submetidas, em uma unidade multipropósito, à secagem a $150{ }^{\circ} \mathrm{C}$, por $30 \mathrm{~min}$, sob fluxo de $\mathrm{He}(30 \mathrm{~mL} /$ min), seguida de redução sob fluxo de $\mathrm{H}_{2}(30 \mathrm{~mL} / \mathrm{min})$ a uma taxa de $10{ }^{\circ} \mathrm{C} / \mathrm{min}$, até $500{ }^{\circ} \mathrm{C}$. A temperatura foi elevada até $800{ }^{\circ} \mathrm{C}$ sob fluxo de $\mathrm{He}(30 \mathrm{~mL} / \mathrm{min})$ a uma taxa de $10{ }^{\circ} \mathrm{C} / \mathrm{min}$ por aproximadamente $10 \mathrm{~min}$. As amostras foram passivadas sob fluxo de $5 \%$ $\mathrm{O}_{2} / \mathrm{He}(30 \mathrm{~mL} / \mathrm{min})$ durante $15 \mathrm{~min}$ à temperatura ambiente. Após redução e passivação, os catalisadores foram colocados na câmara de reação e foram reduzidos sob fluxo de $\mathrm{H}_{2}(30 \mathrm{~mL} / \mathrm{min})$ a uma temperatura de $500{ }^{\circ} \mathrm{C}$ por $1 \mathrm{~h}$. Decorrido esse tempo, a célula foi resfriada até à temperatura ambiente sob fluxo de He. Para a reação entre etanol (Sigma-Aldrich) e $\mathrm{O}_{2}$ com cada catalisador, foi coletado, à temperatura ambiente, sob fluxo de He, um espectro de referência antes do início de cada reação de oxidação parcial no DRIFTS. Os espectros foram obtidos com 256 varreduras, resolução de $4 \mathrm{~cm}^{-1}$, ganho "C" no pré-amplificador e ajuste da abertura de $8 \mathrm{~mm}$ numa faixa de 4000-900 $\mathrm{cm}^{-1}$.

Foi realizada, em seguida, a reação de oxidação parcial do etanol a fim de avaliar as espécies superficiais durante as condições de reação. A corrente gasosa de alimentação à câmara de reação foi obtida a partir de saturação de uma corrente $5 \% \mathrm{O}_{2} / \mathrm{He}$ em etanol a $28{ }^{\circ} \mathrm{C}$, obtendo-se uma razão etanol $/ \mathrm{O}_{2}(1: 2)$ com uma vazão de $30 \mathrm{~mL} / \mathrm{min}$.

Foram obtidos espectros de todos os catalisadores, sob fluxo da mistura reacional (etanol $/ \mathrm{O}_{2}=2$ ), coletados em diversas temperaturas $\left(30,100,200,300,400\right.$ e $\left.500{ }^{\circ} \mathrm{C}\right)$ após $5 \mathrm{~min}$ em cada temperatura. Verificou-se no final, a partir dos experimentos, que o tempo de permanência em cada temperatura não influenciou no perfil resultante do espectro.

\section{RESULTADOS E DISCUSSÃO}

\section{Redução à temperatura programada}

Na Figura 1 são apresentados os perfis de TPR dos suportes utilizados. $\mathrm{O}$ suporte $\mathrm{CeO}_{2}$ apresentou picos de consumo de $\mathrm{H}_{2} \mathrm{em}$ torno de 490 e $810{ }^{\circ} \mathrm{C}$ que podem ser atribuídos à redução do $\mathrm{Ce}$ superficial e do Ce mássico respectivamente. ${ }^{6}$ Os suportes $\gamma-\mathrm{Al}_{2} \mathrm{O}_{3} \mathrm{e}$ $\mathrm{ZrO}_{2}$ se mantiveram estáveis, não apresentando consumo de $\mathrm{H}_{2}$ nas condições testadas. Esta observação é consistente com o resultado obtido por estudos na literatura, ${ }^{7}$ onde se verificou que a $\mathrm{ZrO}_{2}$ é praticamente irredutível nestas condições. ${ }^{8}$ Os suportes de óxidos mistos apresentaram picos de consumo de $\mathrm{H}_{2}$ bem próximos, nos suportes $\mathrm{Ce}_{0,75} \mathrm{Zr}_{0,25} \mathrm{O}_{2}, \mathrm{Ce}_{0,50} \mathrm{Zr}_{0,50} \mathrm{O}_{2}$ e $\mathrm{Ce}_{0,25} \mathrm{Zr}_{0,75} \mathrm{O}_{2}$ podem ser observados máximos a 549, 572 e $602{ }^{\circ} \mathrm{C}$, respectivamente, devido à redução do óxido superficial e parte do óxido mássico que se reduz em temperatura mais baixa devido à presença do $\mathrm{ZrO}_{2} \cdot{ }^{7,9}$ Concluiu-se através da análise dos óxidos mistos que a adição de $\mathrm{ZrO}_{2}$ catalisa a redução do $\mathrm{CeO}_{2}$ mássico. ${ }^{8}$

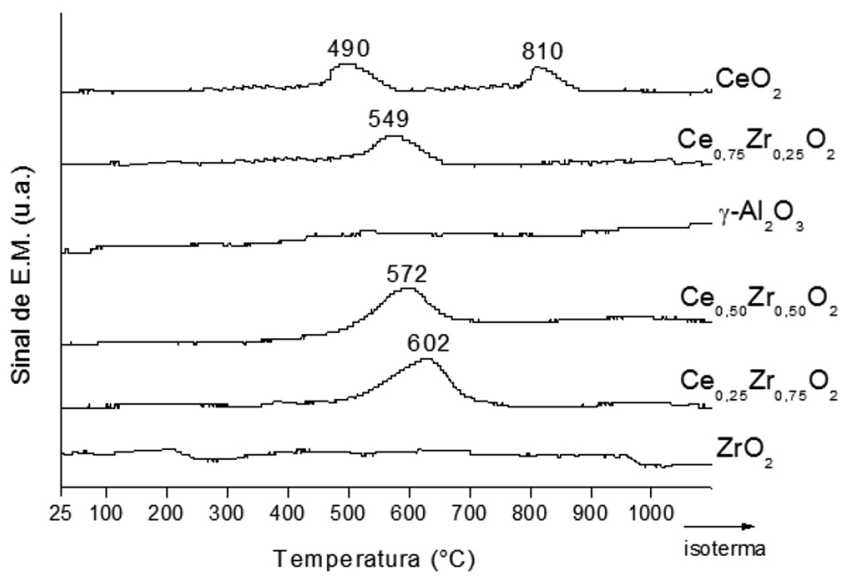

Figura 1. Perfil de TPR dos suportes de óxidos simples e mistos

As Figuras 2 e 3 mostram os perfis de TPR dos catalisadores. $\mathrm{O}$ catalisador $1,5 \% \mathrm{Rh} / \gamma-\mathrm{Al}_{2} \mathrm{O}_{3}$ apresentou um pico de consumo a $154{ }^{\circ} \mathrm{C}$ correspondendo à redução do $\mathrm{Rh}_{2} \mathrm{O}_{3}$ conforme descrito na literatura. ${ }^{10} \mathrm{O}$ catalisador $1,5 \% \mathrm{Rh} / \mathrm{CeO}_{2}$ apresentou picos de consumo de $\mathrm{H}_{2}$ a 96, 224 e $967^{\circ} \mathrm{C}$, referindo-se os dois primeiros picos à existência de íons de $\mathrm{Rh}$ em dois estados diferentes, o primeiro pico à temperatura mais baixa pode ser atribuído a partículas de $\mathrm{Rh}_{2} \mathrm{O}_{3}$ bem dispersas no suporte, enquanto que o segundo pico pode estar relacionado a partículas $\mathrm{Rh}_{2} \mathrm{O}_{3}$ similares ao catalisador mássico, onde o tamanho de partícula controla a cinética de redução. ${ }^{11} \mathrm{O}$ pico a $975^{\circ} \mathrm{C}$ está relacionado claramente à redução dos íons $\mathrm{Ce}$ $\left(\mathrm{Ce}^{+4}\right.$ para $\left.\mathrm{Ce}^{\mathrm{x}+}, \mathrm{x}<4\right) .{ }^{11}$

O catalisador $1,5 \% \mathrm{Rh} / \mathrm{ZrO}_{2}$ apresentou um consumo de $\mathrm{H}_{2}$ a $98 \mathrm{e}$ $211^{\circ} \mathrm{C}$, correspondendo à redução do $\mathrm{Rh}_{2} \mathrm{O}_{3}$ com diferentes tamanhos de partícula, tal como apresentado para $\mathrm{Rh} / \mathrm{CeO}_{2}$.

$\mathrm{O}$ catalisador $1,5 \% \mathrm{Rh} / \mathrm{Ce}_{0,75} \mathrm{Zr}_{0,25} \mathrm{O}_{2}$ apresentou consumo de hidrogênio a $98,135,238$ e $1003{ }^{\circ} \mathrm{C}$, que podem ser atribuídos, respectivamente, o primeiro pico com redução similar ao $\mathrm{Rh}_{2} \mathrm{O}_{3}$ bem disperso, o segundo pico referente a $\mathrm{Rh}_{2} \mathrm{O}_{3}$ mássico, o terceiro à redução de $\mathrm{Rh}_{2} \mathrm{O}_{3}$ em conjunto com $\mathrm{CeO}_{2}$ superficial e o último à redução do óxido de cério mássico, conforme descrito na literatura. ${ }^{11} \mathrm{O}$ catalisador $1,5 \% \mathrm{Rh} / \mathrm{Ce}_{0,25} \mathrm{Zr}_{0,75} \mathrm{O}_{2}$ apresentou consumo de hidrogênio a 144,297 e $1038{ }^{\circ} \mathrm{C}$, enquanto o catalisador $1,5 \%$ $\mathrm{Rh} / \mathrm{Ce}_{0,50} \mathrm{Zr}_{0,50} \mathrm{O}_{2}$ apresentou consumo de hidrogênio a 127 e 268 e $1036^{\circ} \mathrm{C}$, que podem ser atribuídos à redução do $\mathrm{Rh}_{2} \mathrm{O}_{3}$, do $\mathrm{Rh}_{2} \mathrm{O}_{3}$ em conjunto com camadas superficiais de céria, seguida da redução do suporte mássico. ${ }^{11-13}$

Na Tabela 1 é apresentado o consumo de hidrogênio dos catalisadores durante os experimentos de TPR até a temperatura de $1000{ }^{\circ} \mathrm{C}$. Os consumos são coerentes com a redução de $\mathrm{Rh}^{+3} \mathrm{a} \mathrm{Rh}^{0}$ e, no caso dos catalisadores contendo $\mathrm{Ce}$, com a redução parcial do $\mathrm{Ce}^{+4}$. Dessa forma, nota-se um maior consumo de hidrogênio para o catalisador com maior teor de Ce. Assim, obteve-se a seguinte ordem para a redutibiidade dos catalisadores: $1,5 \% \mathrm{Rh} / \mathrm{CeO}_{2}>1,5 \% \mathrm{Rh} /$ $\mathrm{Ce}_{0,75} \mathrm{Zr}_{0,25} \mathrm{O}_{2}>1,5 \% \mathrm{Rh} / \mathrm{Ce}_{0,50} \mathrm{Zr}_{0,50} \mathrm{O}_{2}>1,5 \% \mathrm{Rh} / \mathrm{Ce}_{0,25} \mathrm{Zr}_{0,75} \mathrm{O}_{2}>1,5 \%$ $\mathrm{Rh} / \gamma-\mathrm{Al}_{2} \mathrm{O}_{3}>1,5 \% \mathrm{Rh} / \mathrm{ZrO}_{2}$. Fornasiero e colaboradores concluíram que o aumento do teor de $\mathrm{ZrO}_{2}$ provoca um aumento nos defeitos cristalinos da estrutura cúbica dos óxidos mistos $\mathrm{Ce}_{\mathrm{x}} \mathrm{Zr}_{1-\mathrm{x}} \mathrm{O}_{2},{ }^{14}$ causando uma maior mobilidade do oxigênio da rede cristalina e favorecendo o 


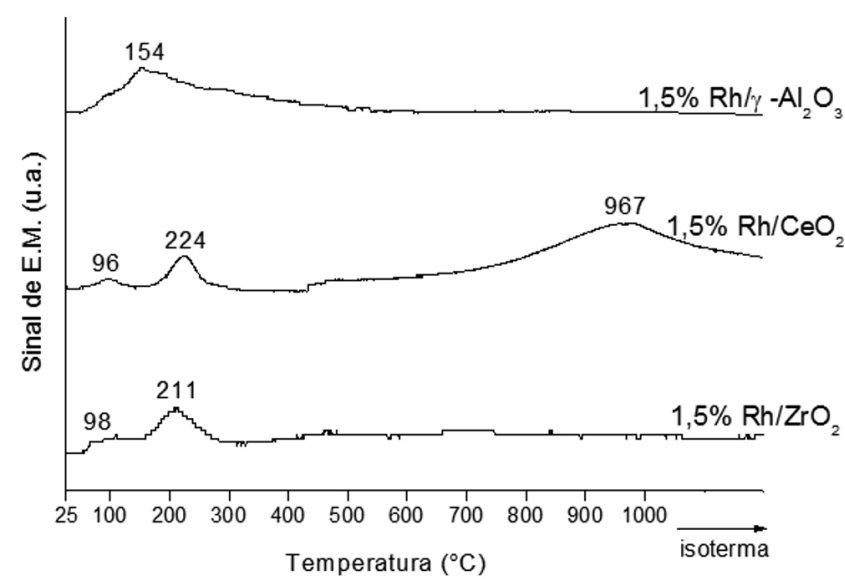

Figura 2. Perfil de TPR dos catalisadores de óxidos simples

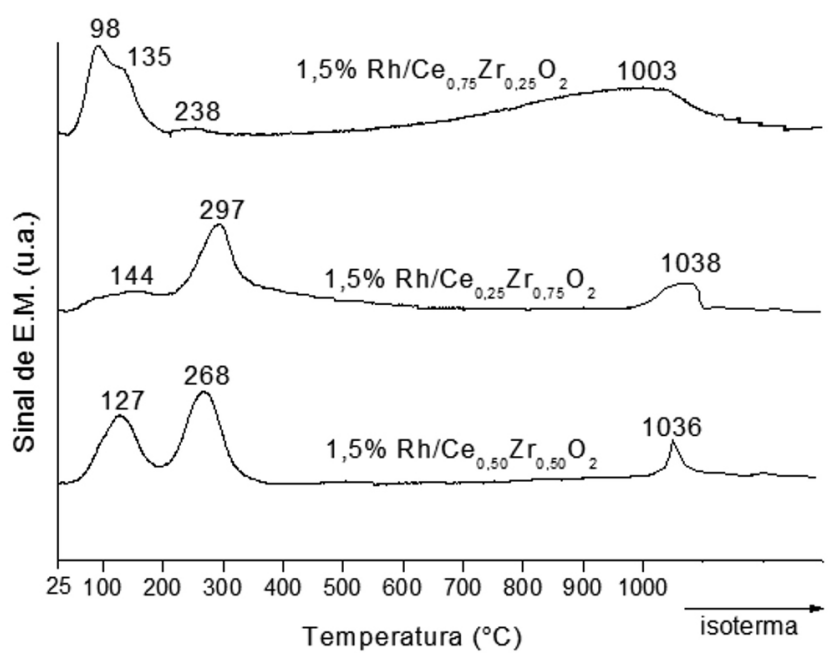

Figura 3. Perfil de TPR dos catalisadores de óxidos mistos

processo de redução do suporte. Este efeito pode explicar o aumento do pico relativo à redução da céria superficial para os catalisadores com menor teor de céria. ${ }^{14}$

Tabela 1. Resultados de TPR

\begin{tabular}{cc}
\hline Catalisador & Consumo de $\mathrm{H}_{2}$ (mol/g cat) $\left(\times 10^{-4}\right)$ \\
\hline $1,5 \% \mathrm{Rh} / \gamma-\mathrm{Al}_{2} \mathrm{O}_{3}$ & 1,9 \\
$1,5 \% \mathrm{Rh} / \mathrm{CeO}_{2}$ & 4,1 \\
$1,5 \% \mathrm{Rh} / \mathrm{ZrO}_{2}$ & 1,8 \\
$1,5 \% \mathrm{Rh} / \mathrm{Ce}_{0,75} \mathrm{Zr}_{0,25} \mathrm{O}_{2}$ & 3,5 \\
$1,5 \% \mathrm{Rh} / \mathrm{Ce}_{0,50} \mathrm{Zr}_{0,50} \mathrm{O}_{2}$ & 3,1 \\
$1,5 \% \mathrm{Rh} / \mathrm{Ce}_{0,25} \mathrm{Zr}_{0,75} \mathrm{O}_{2}$ & 2,6 \\
\hline
\end{tabular}

\section{Desidrogenação do ciclo-hexano}

Na Tabela 2 encontram-se os resultados obtidos na desidrogenação do ciclo-hexano a $270{ }^{\circ} \mathrm{C}$ para os catalisadores em estudo e os valores de dispersão aparente a partir de uma calibração anterior entre taxas de desidrogenação e dispersão.

Para todos os catalisadores, somente o benzeno foi observado como produto da reação, indicando que na faixa de temperatura empregada não ocorreu a reação de hidrogenólise. Na Tabela 2 encontram-se os resultados obtidos na desidrogenação do ciclo-hexano a $270{ }^{\circ} \mathrm{C}$ para os catalisadores em estudo, os valores de dispersão aparente, das taxas de desidrogenação, calculados a partir
Tabela 2. Resultados da reação modelo, valores de dispersão aparente e valores de razão $\mathrm{CO} / \mathrm{Rh}$

\begin{tabular}{lcc}
\hline Catalisador & $\begin{array}{c}\text { Taxa desidrogenação } \\
\left(\times 10^{-3} \text { mol/hg cat }\right)\end{array}$ & $\begin{array}{c}\text { Dispersão aparente } \\
(\%)\end{array}$ \\
\hline $1,5 \% \mathrm{Rh} / \gamma-\mathrm{Al}_{2} \mathrm{O}_{3}$ & 121,1 & 50,1 \\
$1,5 \% \mathrm{Rh} / \mathrm{CeO}_{2}$ & 52,2 & 21,7 \\
$1,5 \% \mathrm{Rh} / \mathrm{ZrO}_{2}$ & 40,5 & 16,8 \\
$1,5 \% \mathrm{Rh} / \mathrm{Ce}_{0,75} \mathrm{Zr}_{0,25} \mathrm{O}_{2}$ & 62,9 & 26,0 \\
$1,5 \% \mathrm{Rh} / \mathrm{Ce}_{0,50} \mathrm{Zr}_{0,50} \mathrm{O}_{2}$ & 51,2 & 21,2 \\
$1,5 \% \mathrm{Rh} / \mathrm{Ce}_{0,25} \mathrm{Zr}_{0,75} \mathrm{O}_{2}$ & 64,8 & 26,8 \\
\hline
\end{tabular}

Condições reacionais: $\mathrm{T}=270{ }^{\circ} \mathrm{C} ; \mathrm{P}=1 \mathrm{~atm} ; \mathrm{WHSV}=170 \mathrm{~h}^{-1}$.

dos resultados do catalisador $1,5 \% \mathrm{Rh} / \gamma-\mathrm{Al}_{2} \mathrm{O}_{3}$, como referência, lembrando que a desidrogenação do ciclo-hexano é insensível à estrutura. ${ }^{10} \mathrm{~A}$ dispersão do catalisador de ródio $\mathrm{Rh} / \mathrm{CeZrO} \mathrm{Z}_{2}$ calculado pela desidrogenação do ciclo-hexano foi relativamente baixa $(\sim 22 \%)$. Dessa forma, a análise da Tabela 2 evidencia que o catalisador $1,5 \%$ $\mathrm{Rh} / \gamma-\mathrm{Al}_{2} \mathrm{O}_{3}$ possui o maior número de sítios ativos. Os catalisadores $\mathrm{Rh} / \mathrm{Ce}_{\mathrm{x}} \mathrm{Zr}_{1-\mathrm{x}} \mathrm{O}_{2}$ apresentaram valores de dispersão aparente similares ao $\mathrm{Rh} / \mathrm{CeO}_{2}$ e em torno de $20 \%$.

\section{DRIFTS}

De acordo com Silva e colaboradores, ${ }^{15}$ na reação de oxidação parcial do etanol em catalisadores de $\mathrm{Pt}$ e Rh, o etanol pode adsorver formando as espécies etóxi que, por sua vez, podem ser desidrogenadas produzindo espécies acetaldeído. A espécie acetaldeído sofre desidrogenação para formar as espécies acetil ou pode também dessorver formando acetaldeído. As espécies acetil podem ser oxidadas às espécies acetato ou podem se decompor formando $\mathrm{CO}, \mathrm{CH}_{4}$ e $\mathrm{H}_{2}$. Da mesma forma, as espécies acetato já formadas podem se decompor a $\mathrm{CH}_{4}$ e $\mathrm{CO}$ e/ou se oxidar a carbonato, que se decompõe a $\mathrm{CO}_{2}$.

Os espectros de DRIFTS sob a mistura reacional etanol/ $\mathrm{O}_{2}$ a diferentes temperaturas no catalisador $1,5 \% \mathrm{Rh} / \gamma-\mathrm{Al}_{2} \mathrm{O}_{3}$ são apresentados na Figura 4a-b. À temperatura ambiente são mostradas bandas em 1386 e $1456 \mathrm{~cm}^{-1}$, atribuídas aos modos de vibração característicos das espécies $\delta_{\mathrm{s}}\left(\mathrm{CH}_{3}\right)$ e $\delta_{\mathrm{as}}\left(\mathrm{CH}_{3}\right)$, respectivamente. $\mathrm{O}$ catalisador já apresenta atividade à temperatura ambiente, pois é observada a banda a $1576 \mathrm{~cm}^{-1}$ correspondente ao estiramento assimétrico da espécie acetato $\left(v_{\text {as }}(\mathrm{OCO})\right)$. Também é observada uma banda em $1631 \mathrm{~cm}^{-1}$ cuja atribuição é controversa. Entretanto, muitos autores sugerem que se trata da formação da espécie acetil, como um intermediário que faz parte do mecanismo de reação de decomposição de compostos oxigenados na superfície do metal. ${ }^{16-21}$ Esses compostos oxigenados são produzidos pela desidrogenação de espécies etóxi, confirmando a atividade do catalisador de Rh à temperatura ambiente. De acordo com a literatura, o modo de vibração $v(\mathrm{CO})$ correspondente à espécie acetil é observado a partir de $1610 \mathrm{~cm}^{-1}$ no $\mathrm{Pd}(110)$ até $1684 \mathrm{~cm}^{-1}$ no catalisador $\mathrm{Pd} / \mathrm{CeO}_{2} \cdot{ }^{17,18}$ A descarbonilação do etanol também prossegue via intermediário acetil nos outros metais do Grupo VIII, como a Pt (111) e o Ni (111). ${ }^{19,20}$ Observou-se também que a banda $v(\mathrm{CO})$ da espécie acetil também varia em função da natureza do metal. Zhao e colaboradores mostraram que a banda $v(\mathrm{CO})$ da espécie acetil foi em $1647 \mathrm{~cm}^{-1}$ na Pt (111). ${ }^{19}$ Além disso, Shekhar e colaboradores relataram que a espécie acetil em superfícies metálicas apresentam um alto grau de retroligação e a frequência do estiramento $\mathrm{CO}$ é fortemente dependente do número de coordenação dos átomos da superfície metálica. ${ }^{17}$ Consequentemente, a banda em $1631 \mathrm{~cm}^{-1}$ poderia ser 
atribuída ao modo vibracional $v(\mathrm{CO})$ da espécie acetil em $\mathrm{Rh}$. À temperatura ambiente é observada também uma banda em 2977 $\mathrm{cm}^{-1}$, atribuída ao estiramento assimétrico $\left(\mathrm{v}_{\mathrm{as}}\left(\mathrm{CH}_{3}\right)\right) .{ }^{15}$
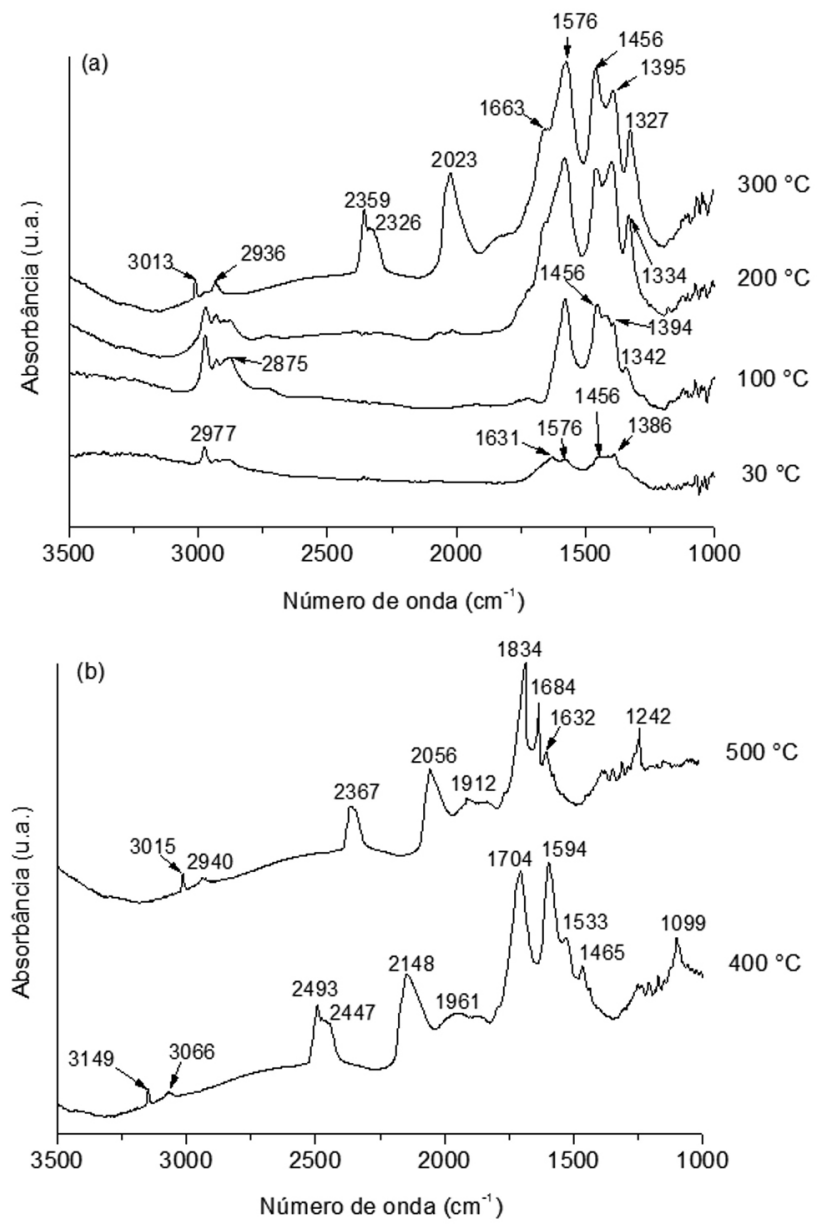

Figuras 4. Espectros de DRIFTS obtidos sob a mistura reacional etanol/O $\mathrm{O}_{2}$ a diferentes temperaturas no catalisador $1,5 \% R h / \gamma-\mathrm{Al}_{2} \mathrm{O}_{3}$. Razão etanol/ $\mathrm{O}_{2}=2$

Conforme descrito na literatura, alcoóis como metanol ou etanol se adsorvem dissociativamente na superfície do catalisador, através da quebra da ligação $\mathrm{O}-\mathrm{H}$, com formação de alcóxido, que são as espécies metóxi ou etóxi. ${ }^{15}$ As bandas observadas na região entre 2800-2980 $\mathrm{cm}^{-1}$ são atribuídas aos modos de vibração do estiramento da ligação $\mathrm{C}-\mathrm{H}\left(\mathrm{v}_{\mathrm{as}}\left(\mathrm{CH}_{3}\right)\right.$ e $\mathrm{v}_{\mathrm{s}}\left(\mathrm{CH}_{3}\right)$ e $\mathrm{v}_{\mathrm{as}}\left(\mathrm{CH}_{2}\right)$ e $\left.\mathrm{v}_{\mathrm{s}}\left(\mathrm{CH}_{2}\right)\right)$ das espécies etóxi. $\mathrm{O}$ aquecimento até $100{ }^{\circ} \mathrm{C}$ praticamente não causa alterações no espectro. Quando a temperatura chega a $100{ }^{\circ} \mathrm{C}$, a intensidade das bandas etóxi diminui significativamente, sendo observado um aumento da banda a $1576 \mathrm{~cm}^{-1}$, correspondente ao estiramento assimétrico da espécie acetato $\left(\mathrm{v}_{\mathrm{as}}(\mathrm{OCO})\right)$ e o aparecimento de novas bandas em 1394 e $2875 \mathrm{~cm}^{-1}$. De acordo com a literatura, ${ }^{15,22}$ estas bandas correspondem à deformação angular do $\mathrm{CH}_{3}\left(\delta_{\mathrm{s}}\left(\mathrm{CH}_{3}\right)\right)$ e ao modo vibracional do estiramento da ligação $\mathrm{C}-\mathrm{H}\left(\mathrm{v}_{\mathrm{s}}\left(\mathrm{CH}_{2}\right)\right)$, respectivamente, indicando com isso, a oxidação das espécies etóxi para produzir as espécies acetato. A $200{ }^{\circ} \mathrm{C}$ não houve alteração no espectro. A $300{ }^{\circ} \mathrm{C}$ verifica-se um grande aumento das intensidades das bandas relativas às espécies acetato, enquanto que as bandas atribuídas às espécies etóxi já desapareceram totalmente. Nota-se, além disso, a presença de uma banda em $2023 \mathrm{~cm}^{-1}$, relativa à adsorção de $\mathrm{CO}$ na forma de ponte sobre o Rh metálico. ${ }^{23}$ Nota-se um ombro em $1663 \mathrm{~cm}^{-1}$, que pode ser atribuído à espécie acetil (v (CO)), que com o aumento de temperatura desaparece..$^{15}$ Observa-se também a presença de bandas entre $2300-2400 \mathrm{~cm}^{-1}$ referentes à presença de
$\mathrm{CO}_{2}$ na fase gasosa. A presença de uma banda em $3013 \mathrm{~cm}^{-1}$ refere-se à espécie $\mathrm{CH}_{4}$. A presença de $\mathrm{CO}_{2}$ pode ser atribuída à decomposição das espécies carbonato, que são formadas a partir da oxidação das espécies acetato. ${ }^{16-18}$

A $400{ }^{\circ} \mathrm{C}$ nota-se uma diminuição da intensidade das bandas correspondentes às espécies acetato. Verifica-se, também, a presença de uma banda em $1704 \mathrm{~cm}^{-1}$, relativa ao acetaldeído. A banda em $3149 \mathrm{~cm}^{-1}$ é referente às espécies hidroxilas ligadas intermolecularmente por pontes de hidrogênio na superfície. ${ }^{24}$ Acima de $400{ }^{\circ} \mathrm{C}$, as espécies acetato não são mais detectadas, sendo observada a presença das bandas correspondentes às espécies carbonato. Observa-se também a presença de uma banda em $2367 \mathrm{~cm}^{-1}$ referente à presença de $\mathrm{CO}_{2}$ na fase gasosa. Não foi observada, a $500{ }^{\circ} \mathrm{C}$, a banda relativa ao acetaldeído, provavelmente, tanto pela conversão de acetaldeído a $\mathrm{CH}_{4} \mathrm{e} \mathrm{CO}$, quanto pela interação entre o Rh e uma configuração cíclica, obtida da perda de um átomo de $\mathrm{H}$ por parte das espécies etóxi, que adsorvem como um oxametaciclo [(ads) $-\mathrm{OCH}_{2}-\mathrm{CH}_{2}$-(ads)], que pode ser oxidado a $\mathrm{CO}_{2} \cdot{ }^{15,16}$

$\mathrm{Na}$ Figura 5, são apresentados os espectros de DRIFTS sob a mistura etanol $/ \mathrm{O}_{2}$ a diferentes temperaturas para o catalisador $1,5 \%$ $\mathrm{Rh} / \mathrm{CeO}_{2}$. Podem ser notadas, à temperatura ambiente, as bandas em 1395, 1565, 1607 e $2070 \mathrm{~cm}^{-1}$, referentes aos modos de vibração do estiramento da ligação $\mathrm{C}-\mathrm{H} \mathrm{v}_{\mathrm{s}}\left(\mathrm{CH}_{3}\right)$, ao estiramento assimétrico da espécie acetato $\left(v_{\text {as }}(\mathrm{OCO})\right)$, a banda em $1607 \mathrm{~cm}^{-1}$ poderia ser atribuída ao modo vibracional $v(\mathrm{CO})$ da espécie acetil em $\mathrm{Rh}$ e ao $\mathrm{CO}$ adsorvido sobre grandes partículas de $\mathrm{Rh}$, respectivamente. ${ }^{25,26}$ Foi observada a presença de uma banda em $1757 \mathrm{~cm}^{-1}$, atribuída ao modo de vibração $v(\mathrm{C}=\mathrm{O})$ do acetaldeído adsorvido. Verificou-se também uma banda em $1929 \mathrm{~cm}^{-1}$, onde alguns autores atribuem à adsorção do CO na forma de ponte sobre as partículas de Rh e uma banda em $2263 \mathrm{~cm}^{-1}$ atribuída à formação de $\mathrm{CO}_{2} \cdot{ }^{15,25,27} \mathrm{~A}$ região com bandas entre $1910 \mathrm{e} 1760 \mathrm{~cm}^{-1}$ corresponde à forma de ponte ou multicoordenada da adsorção de $\mathrm{CO}$ no ródio metálico. ${ }^{28}$ De acordo com a literatura, a formação de $\mathrm{CO}$ a baixas temperaturas pode estar associada à decomposição de espécies desidrogenadas..$^{15}$ As bandas em 3485 e $3401 \mathrm{~cm}^{-1}$, que aparecem à temperatura ambiente, sugerem espécies hidroxilas ligadas intermolecularmente por pontes de hidrogênio referentes à água adsorvida no catalisador. ${ }^{24,29}$ Nota-se que com $\mathrm{o}$ aumento de temperatura, essas bandas referentes à vibração $\mathrm{O}-\mathrm{H}$ desaparecem totalmente. A variedade de espécies adsorvidas indica uma maior atividade para este catalisador à temperatura ambiente.

$\mathrm{O}$ aumento da temperatura até $100{ }^{\circ} \mathrm{C}$ quase não provocou nenhuma mudança significativa no espectro. Com o aquecimento a $200{ }^{\circ} \mathrm{C}$, a intensidade das bandas etóxi diminui e uma banda

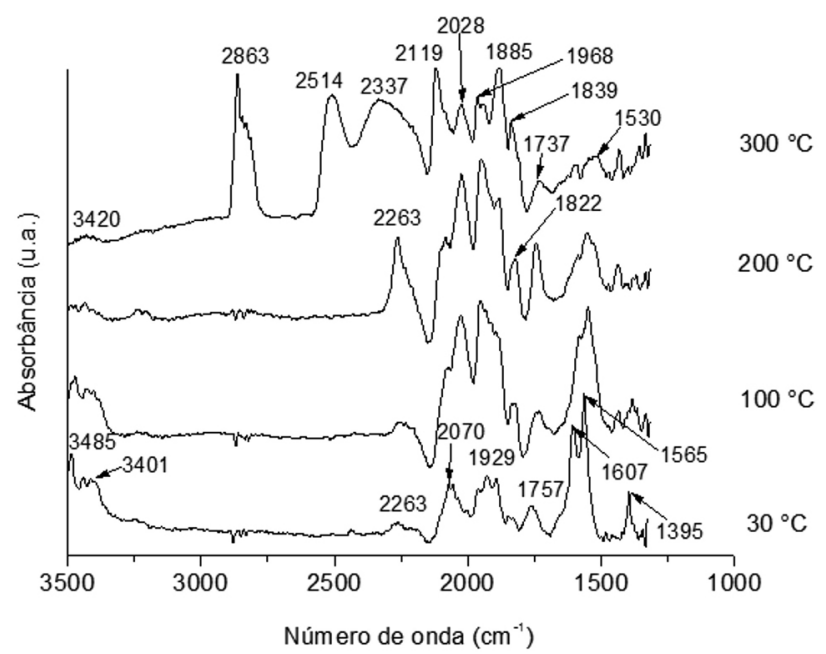

Figura 5. Espectros de DRIFTS obtidos sob a mistura reacional etanol/O $\mathrm{O}_{2}$ a diferentes temperaturas no catalisador $1,5 \% \mathrm{Rh} / \mathrm{CeO}_{2}$. Razão etanol/ $\mathrm{O}_{2}=2$ 
característica das espécies acetato $\left(1576 \mathrm{~cm}^{-1}\right)$ aumenta. ${ }^{15}$ É possível verificar também a presença de uma banda em $1757 \mathrm{~cm}^{-1}$ atribuída ao acetaldeído adsorvido.

A $300{ }^{\circ} \mathrm{C}$, a banda que aparece em $2863 \mathrm{~cm}^{-1}$, encontra-se na região entre $2800-2980 \mathrm{~cm}^{-1}$ e corresponde ao modo de vibração do estiramento da ligação $\mathrm{C}-\mathrm{H}\left(\mathrm{v}_{\mathrm{s}}\left(\mathrm{CH}_{2}\right)\right)$ da espécie etóxi. Nota-se uma diminuição da intensidade das bandas atribuídas às espécies acetato em $1530 \mathrm{~cm}^{-1}$ e acetaldeído em $1737 \mathrm{~cm}^{-1}$. É importante observar o aparecimento de uma banda larga em $2337 \mathrm{~cm}^{-1}$, referente ao $\mathrm{CO}_{2}$ na fase gasosa, sugerindo com isso a decomposição das espécies acetato via carbonato. ${ }^{28}$ Nota-se ainda a presença de uma banda em $2028 \mathrm{~cm}^{-1}$, relativa à adsorção de $\mathrm{CO}$ na forma de ponte sobre o Rh metálico. ${ }^{23} \mathrm{O}$ desaparecimento de bandas da espécie etóxi juntamente com a diminuição da intensidade das bandas referentes à espécie acetaldeído, a temperaturas elevadas, para catalisadores à base de $\mathrm{Rh}$ sugere também que pode ter ocorrido a interação entre o Rh e uma configuração cíclica, obtida da perda de um átomo de $\mathrm{H}$ por parte das espécies etóxi, que adsorvem como um oxametaciclo [(ads)- $\mathrm{OCH}_{2}$ $-\mathrm{CH}_{2}$-(ads)], que pode ser oxidado a $\mathrm{CO}_{2} .15 \cdot 16$ Acima de $300{ }^{\circ} \mathrm{C}$ não foi possível visualizar nenhum espectro, sugerindo com isso a desativação do catalisador, provavelmente por deposição de coque.

A partir da comparação dos espectros obtidos para os catalisadores $\mathrm{Rh} / \gamma-\mathrm{Al}_{2} \mathrm{O}_{3} \mathrm{e} \mathrm{Rh} / \mathrm{CeO}_{2}$, podem ser verificadas algumas diferenças significativas. À temperatura ambiente já se observa a presença da banda atribuída à espécie acetaldeído no catalisador $\mathrm{Rh} / \mathrm{CeO}_{2}$, que só aparece no catalisador $\mathrm{Rh} / \gamma-\mathrm{Al}_{2} \mathrm{O}_{3}$ a $400{ }^{\circ} \mathrm{C}$. Na realidade, os espectros de DRIFTS em temperaturas mais altas $\left(300-400{ }^{\circ} \mathrm{C}\right)$ revelam uma grande formação de espécies acetato no catalisador $\mathrm{Rh} / \gamma-\mathrm{Al}_{2} \mathrm{O}_{3}$ enquanto que isso não ocorre no catalisador $\mathrm{Rh} / \mathrm{CeO}_{2}$, onde o acetato já teria se oxidado. Estes resultados sugerem que o catalisador $\mathrm{Rh} /$ $\mathrm{CeO}_{2}$ é bem mais ativo para a oxidação do acetato a carbonato do que o $\mathrm{Rh} / \gamma-\mathrm{Al}_{2} \mathrm{O}_{3}$, devido à desidrogenação das espécies etóxi logo à temperatura ambiente, sugerindo com isso que a oxidação dessas espécies desidrogenadas via carbonato é favorecida.

É observada a formação de bandas menos intensas relativas às espécies acetato, ou seja, as bandas relativas às espécies carbonato aparecem com maior intensidade que as bandas das espécies acetato e, assim, a taxa da reação de oxidação das espécies acetato a carbonato e de sua decomposição a $\mathrm{CO}_{2}$ são promovidas no catalisador suportado em $\mathrm{CeO}_{2}$, provavelmente devido às propriedades redox deste suporte.

A decomposição das espécies etóxi pode ocorrer de duas maneiras: decomposição a $\mathrm{CH}_{4}$, $\mathrm{CO}$ e $\mathrm{H}_{2}$ ou desidrogenação para formar acetaldeído e espécies acetil. ${ }^{30}$ Essas espécies desidrogenadas podem formar acetato através da oxidação, com a participação do $\mathrm{CeO}_{2}$ utilizando os sítios de oxigênio disponíveis em sua superfície. Com a adição de $\mathrm{O}_{2}$, na reação de oxidação parcial, ocorre a formação de espécies acetato, pois o $\mathrm{O}_{2}$ supre a necessidade de ocupar as vacâncias de oxigênio que vão sendo formadas durante a reação de oxidação parcial do etanol.

Os espectros de DRIFTS sob a mistura etanol $/ \mathrm{O}_{2}$ a diferentes temperaturas no catalisador $1,5 \% \mathrm{Rh} / \mathrm{Ce}_{0,50} \mathrm{Zr}_{0,50} \mathrm{O}_{2}$ são apresentados na Figura 6a-b. À temperatura ambiente, o espectro apresentou as bandas em 1049, 1157, 1301 e $1429 \mathrm{~cm}^{-1}$ características dos diferentes modos vibracionais das espécies etóxi $(\mathrm{V}(\mathrm{C}-\mathrm{O})$ em ponte ou bidentado, $v(\mathrm{C}-\mathrm{O})$ monodentado, $\delta_{\mathrm{s}}\left(\mathrm{CH}_{3}\right)$ e $\delta_{\mathrm{as}}\left(\mathrm{CH}_{3}\right)$, respectivamente). ${ }^{15}$ Nesta mesma temperatura também apareceram bandas de adsorção de monóxido de carbono sobre as partículas do metal em 1888 (ponte) e 2040 (linear) $\mathrm{cm}^{-1} .{ }^{27} \mathrm{~A}$ banda que aparece em $1564 \mathrm{~cm}^{-1}$ é atribuída ao modo de vibração da espécie acetato $\left(\mathrm{v}_{\text {as }}(\mathrm{OCO})\right)$, o que indica que as espécies etóxi sofreram oxidação produzindo as espécies acetato, já à temperatura ambiente.

$\mathrm{O}$ aquecimento até $100{ }^{\circ} \mathrm{C}$ ocasionou um aumento da intensidade da banda em $1560 \mathrm{~cm}^{-1}$, atribuída ao modo de vibração da espécie acetato $\left(\mathrm{v}_{\mathrm{as}}(\mathrm{OCO})\right)$, com consequente diminuição das bandas das espécies
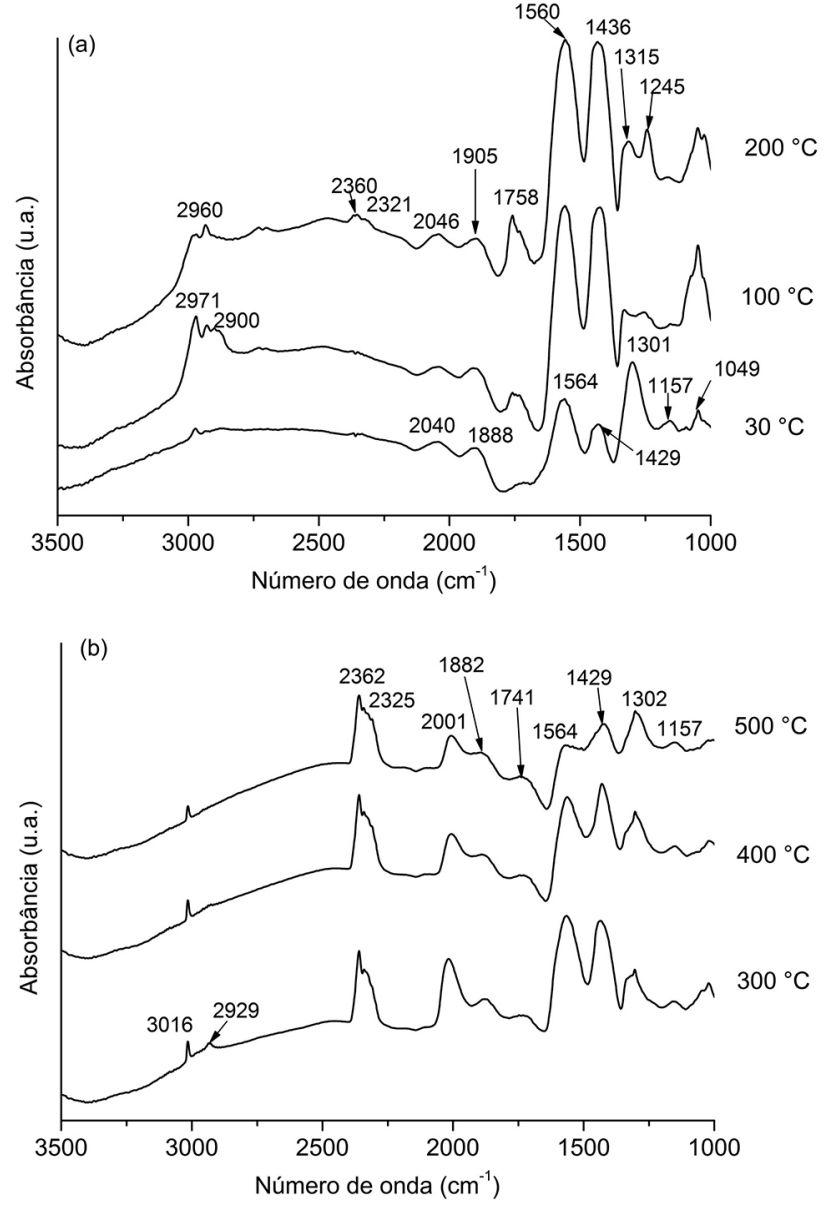

Figura 6. Espectros de DRIFTS obtidos sob a mistura reacional etanol/ $\mathrm{O}_{2}$ a diferentes temperaturas no catalisador $1,5 \% \mathrm{Rh} / \mathrm{Ce} e_{0,50} \mathrm{Zr}_{0,50} \mathrm{O}_{2}$. Razão etanol $/ \mathrm{O}_{2}=2$

etóxi. A banda em $2046 \mathrm{~cm}^{-1}$ está associada ao etanol molecularmente adsorvido nos sítios ácidos de Lewis do óxido. ${ }^{15} \mathrm{~A}$ banda que aparece em $1758 \mathrm{~cm}^{-1}$ é atribuída ao acetaldeído. As bandas que apareceram em $2900 \mathrm{~cm}^{-1}$ são atribuídas ao estiramento simétrico do $\mathrm{CH}_{2}\left(\mathrm{vs} \mathrm{CH}_{2}\right) \mathrm{e}$ em $2971 \mathrm{~cm}^{-1}$, ao estiramento assimétrico do $\mathrm{CH}_{3}:\left(\mathrm{v}_{\mathrm{as}} \mathrm{CH}_{3}\right)$. A $200^{\circ} \mathrm{C}$ apareceram as bandas características do $\mathrm{CO}_{2}$ na fase gasosa em 2321 e $2360 \mathrm{~cm}^{-1}$. A partir de $300{ }^{\circ} \mathrm{C}$ houve um aumento da intensidade das bandas entre $2300-2400 \mathrm{~cm}^{-1}$ associadas ao $\mathrm{CO}_{2}$ na fase gasosa. ${ }^{28}$ Observa-se também uma diminuição da intensidade da banda relativa à espécie acetato em $1564 \mathrm{~cm}^{-1}$. A diminuição da intensidade das bandas referentes aos modos de vibração $v(C=\mathrm{O})$ do acetaldeído e o desaparecimento das espécies etóxi, a temperaturas elevadas, ocorrem

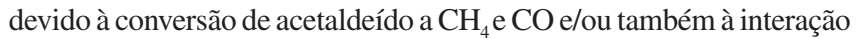
entre o Rh e uma configuração cíclica, obtida da perda de um átomo de $\mathrm{H}$ por parte das espécies etóxi, que adsorvem como um oxametaciclo [(ads) $-\mathrm{OCH}_{2}-\mathrm{CH}_{2}$-(ads)], que pode ser oxidado a $\mathrm{CO}_{2} \cdot{ }^{15,16}$ Esta presença de $\mathrm{CO}_{2}$ pode ser atribuída à decomposição das espécies carbonato que são formadas a partir da oxidação das espécies acetato. Ainda pode ser notada a presença de uma pequena banda atribuída ao acetaldeído mesmo durante a reação a $500{ }^{\circ} \mathrm{C}$.

Para os catalisadores $1,5 \% \mathrm{Rh} / \mathrm{Ce}_{0,25} \mathrm{Zr}_{0,75} \mathrm{O}_{2}$ e $1,5 \% \mathrm{Rh} /$ $\mathrm{Ce}_{0,75} \mathrm{Zr}_{0,25} \mathrm{O}_{2}$ os comportamentos foram similares. O catalisador $1,5 \%$ $\mathrm{Rh} / \mathrm{ZrO}_{2}$ se mostrou o menos ativo entre os testados.

Quando comparados todos os catalisadores, nota-se que o catalisador $1,5 \% \mathrm{Rh} / \mathrm{CeO}_{2}$ pareceu ser mais ativo para uma maior formação de espécies acetato, o que pode ser atribuído a sua maior capacidade de troca de oxigênio, levando à formação de $\mathrm{CH}_{4}$ e $\mathrm{CO}_{2}$. 
Pode-se concluir que a taxa das reações de oxidação das espécies etóxi a acetato e de sua decomposição a $\mathrm{CO}_{2}$, na forma gasosa, foram promovidas pelo catalisador $1,5 \% \mathrm{Rh} / \mathrm{CeO}_{2}$, podendo ser atribuído às propriedades redox do suporte. ${ }^{28}$

A Tabela 3 apresenta os resultados das frequências vibracionais e dos modos de estiramentos para as diferentes espécies formadas após adsorção de etanol nos diferentes catalisadores a $30{ }^{\circ} \mathrm{C}$.

Tabela 3. Frequências vibracionais e modos de estiramentos para as diferentes espécies formadas, após adsorção de etanol, nos diferentes catalisadores a $30^{\circ} \mathrm{C}$

\begin{tabular}{|c|c|c|c|}
\hline Modos vibracionais & $\begin{array}{c}1,5 \% \mathrm{Rh} / \\
\gamma-\mathrm{Al}_{2} \mathrm{O}_{3}\end{array}$ & $\begin{array}{c}1,5 \% \mathrm{Rh} / \\
\mathrm{CeO}_{2}\end{array}$ & $\begin{array}{c}1,5 \% \mathrm{Rh} / \\
\mathrm{Ce}_{0,50} \mathrm{Zr}_{0,50} \mathrm{O}_{2} \\
\end{array}$ \\
\hline \multicolumn{4}{|l|}{ Etanol - Espécies Etóxi } \\
\hline$v_{\text {as }}\left(\mathrm{CH}_{3}\right)$ & 2977 & & 2971 \\
\hline$\delta_{\text {as }}\left(\mathrm{CH}_{3}\right)$ & 1456 & & 1429 \\
\hline$\delta_{\mathrm{s}}\left(\mathrm{CH}_{3}\right)$ & 1386 & 1395 & 1301 \\
\hline$v(\mathrm{CO})$ mono & & & 1157 \\
\hline$v(\mathrm{CO}) \mathrm{bi}$ & & 1929 & 1049 \\
\hline \multicolumn{4}{|l|}{$\mathrm{CO}$} \\
\hline$v(\mathrm{CO})$ linear & & 2070 & 2040 \\
\hline$v(\mathrm{CO})$ em ponte & & & 1888 \\
\hline \multicolumn{4}{|l|}{ Acetato } \\
\hline $\mathrm{v}_{\mathrm{as}}(\mathrm{OCO})$ & 1576 & 1565 & \\
\hline \multicolumn{4}{|l|}{ Acetil } \\
\hline$v(\mathrm{CO})$ & 1631 & 1607 & \\
\hline \multicolumn{4}{|l|}{ Acetaldeído } \\
\hline$v \operatorname{CO}\left(\eta_{1}\right)$ & & 1757 & \\
\hline \multicolumn{4}{|l|}{$\mathrm{H}_{2} \mathrm{O}-\mathrm{OH}$} \\
\hline$v(\mathrm{OH})$ & & 3401 e 3485 & \\
\hline
\end{tabular}

Esses resultados de DRIFTS para os catalisadores de Rh suportados permitem estabelecer um mecanismo geral proposto para a reação de oxidação parcial do etanol. A Figura 7 apresenta o mecanismo proposto para a reação de oxidação parcial do etanol nos catalisadores. Os caminhos de reação e seletividades dos produtos observados durante a decomposição de alcoóis e aldeídos na superfície do metal de transição parecem bastante diversificados e fortemente dependentes da identidade do metal e da estrutura molecular dos reagentes. ${ }^{16}$ Como exemplo disso, seria a formação sugerida dos oxametaciclos a partir da adsorção do etanol e alcoóis superiores no Rh. ${ }^{16}$

Essa reação de oxidação parcial do etanol nos catalisadores de Rh suportados ocorre através de uma etapa inicial de adsorção

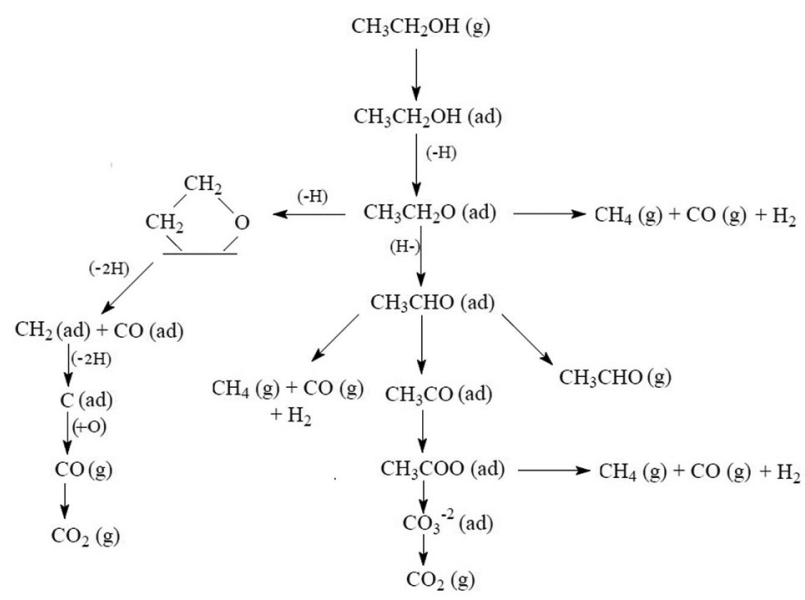

Figura 7. Mecanismo da reação de oxidação parcial do etanol dissociativa do etanol na superfície do catalisador e, em paralelo, a formação de uma espécie etóxi. Esta espécie etóxi pode perder um átomo de $\mathrm{H}$, proveniente do grupo metila terminal, formando um intermediário oxametaciclo [(ads)- $\mathrm{OCH}_{2}-\mathrm{CH}_{2}$-(ads)], que interage com o Rh. Este intermediário por decomposição gera $\mathrm{CO}_{2}$. Ou, ainda, a espécie etóxi poderá sofrer desidrogenação podendo gerar as espécies acetaldeído e acetil. Essas espécies desidrogenadas são oxidadas gerando as espécies acetato (carboxilato) que são posteriormente oxidadas a carbonato. As espécies desidrogenadas a acetato podem sofrer decomposição a $\mathrm{CH}_{4}, \mathrm{CO}$ e $\mathrm{H}_{2}$ ou então, o acetato pode se oxidar a carbonato, gerando $\mathrm{CO}_{2}$ gasoso. ${ }^{31}$ Nesse trabalho, para essa reação de oxidação parcial do etanol não foi possível detectar as bandas correspondentes ao intermediário oxametaciclo, que de acordo com a literatura ocorrem abaixo de $1000 \mathrm{~cm}^{-1}$, devido à baixa resolução dos espectros de DRIFTS nessa região. ${ }^{15} \mathrm{~A}$ frequência de vibração esperada para espécies de oxametaciclos num anel de cinco membros, que são mais estáveis no Rh, aparecem em comprimentos de onda acima de $1000 \mathrm{~cm}^{-1}$, semelhantemente às espécies etóxi.15

Foram realizadas, para cada suporte, comparações dos espectros de DRIFTS das reações de oxidação parcial do etanol com seus respectivos catalisadores. A razão etanol/ $\mathrm{O}_{2}$ para os suportes foi a mesma que a utilizada para os catalisadores.

A Figura 1Sa,b, material suplementar, apresenta os espectros de DRIFTS do suporte $\gamma-\mathrm{Al}_{2} \mathrm{O}_{3}$. O catalisador $1,5 \% \mathrm{Rh} / \gamma-\mathrm{Al}_{2} \mathrm{O}_{3}$ apresentou uma melhor atividade para a reação do etanol a acetato, observando-se, à temperatura ambiente, a maior formação de espécies acetato do que no seu suporte $\gamma-\mathrm{Al}_{2} \mathrm{O}_{3}$. Para o suporte, à temperatura ambiente, só há uma banda, muito fraca, em $1581 \mathrm{~cm}^{-1}$, atribuída ao modo de vibração da espécie acetato $\left(\mathrm{v}_{\mathrm{as}}(\mathrm{OCO})\right)$. $\mathrm{O}$ aquecimento a $100{ }^{\circ} \mathrm{C}$ leva ao aumento da intensidade da banda referente à espécie acetato em $1573 \mathrm{~cm}^{-1}$ e à formação de bandas em 2316 e $2360 \mathrm{~cm}^{-1}$, referentes à espécie $\mathrm{CO}_{2}$, na forma gasosa. O aquecimento a $200{ }^{\circ} \mathrm{C}$ provocou adicionalmente o aparecimento de uma banda em $1768 \mathrm{~cm}^{-1}$, referente ao acetaldeído. Com o aumento da temperatura, a intensidade das bandas em 2725, 2875 e $2967 \mathrm{~cm}^{-1}$, referentes ao estiramento $\mathrm{C}-\mathrm{H}$, diminui. ${ }^{32} \mathrm{~A}$ temperaturas elevadas, houve desaparecimento da espécie acetaldeído e aumento da intensidade das espécies acetato. Durante a reação de oxidação parcial do etanol no suporte $\gamma-\mathrm{Al}_{2} \mathrm{O}_{3}$ surgiram os seguintes intermediários de reação: bandas referentes à espécie acetato, acetaldeído e espécies precursoras para formação de eteno. As taxas da reação de oxidação das espécies etóxi a acetato e de sua decomposição a $\mathrm{CO}_{2}$ foram melhor promovidas no catalisador.

A Figura 2Sa,b, material suplementar, apresenta os espectros de DRIFTS para o suporte $\mathrm{CeO}_{2}$. O catalisador $1,5 \% \mathrm{Rh} / \mathrm{CeO}_{2}$ obteve uma melhor atividade para a formação de espécies carbonato (oxidação das espécies acetato) se comparado ao respectivo suporte. Após a adsorção do etanol na superfície do $\mathrm{CeO}_{2}$, à temperatura ambiente, foram obtidas as seguintes bandas: 1108, 1286, 1488, 1641, 2323, 2360, 2830 e $2894 \mathrm{~cm}^{-1}$. As bandas em 2830 e $2894 \mathrm{~cm}^{-1}$ referem-se ao modo de vibração $v\left(\mathrm{CH}_{3}, \mathrm{CH}_{2}\right)$, em 2323 e $2360 \mathrm{~cm}^{-1}$ foram atribuídas ao $\mathrm{CO}_{2}$ na forma gasosa, em $1641 \mathrm{~cm}^{-1}$ foi atribuída à formação de água que, com o aumento da temperatura, tem sua intensidade diminuída até seu completo desaparecimento, em 1488 $\mathrm{cm}^{-1}$ corresponde ao modo vibracional $\delta_{\text {as }}\left(\mathrm{CH}_{3}, \mathrm{CH}_{2}\right)$, em $1286 \mathrm{~cm}^{-1}$ refere-se à deformação angular da ligação $\mathrm{OH}$ do etanol adsorvido no suporte $\mathrm{CeO}_{2}$ e em $1108 \mathrm{~cm}^{-1}$ ao modo vibracional v(C-O), atribuído à espécie etóxi na superfície do suporte. ${ }^{32}$ Com o aquecimento a 200 ${ }^{\circ} \mathrm{C}$, ocorre o aparecimento de bandas atribuídas ao modo de vibração da espécie acetato $\left(v_{\text {as }}(\mathrm{OCO})\right)$ em 1546 e em $1430 \mathrm{~cm}^{-1}$, referentes ao modo de vibração da espécie acetato $\left(\mathrm{v}_{\mathrm{s}}(\mathrm{OCO})\right)$, o que indica que as espécies etóxi sofreram oxidação produzindo as espécies acetato. A banda em $1712 \mathrm{~cm}^{-1}$ é atribuída à formação da espécie acetaldeído, que ocorre pela desidrogenação oxidativa de espécies etóxi após 
aquecimento das amostras. ${ }^{32}$ Com o aumento da temperatura, a $500{ }^{\circ} \mathrm{C}$, houve uma leve diminuição da absorção de todas as bandas e não houve mais nenhuma evidência de aparecimento de espécies etóxi, provavelmente pela desidrogenação a acetaldeído.

No catalisador $1,5 \% \mathrm{Rh} / \mathrm{CeO}_{2}$ à temperatura ambiente já houve desidrogenação das espécies etóxi para formação da espécie acetaldeído na presença do Rh e há a presença de muitas bandas de espécies acetato. Entretanto, no suporte, as bandas das espécies acetato só começaram a aparecer a $200^{\circ} \mathrm{C}$. Dessa forma, o catalisador apresentou melhor atividade para rendimento da reação de desidrogenação do etanol a acetaldeído, ainda com presença das espécies acetato. Logo, as taxas das reações de oxidação das espécies etóxi a acetato e de sua decomposição a $\mathrm{CO}_{2}$ são promovidas no catalisador $1,5 \% \mathrm{Rh} / \mathrm{CeO}_{2}$. Esses resultados são semelhantes ao encontrado na literatura para os catalisadores $\mathrm{Pd} / \mathrm{CeO}_{2}$ e $\mathrm{Pt} / \mathrm{CeO}_{2}$, cujas atividades foram comparadas ao suporte $\mathrm{CeO}_{2} \cdot{ }^{28,32}$

Na Figura 3S, material suplementar, são apresentados os espectros de DRIFTS para o suporte $\mathrm{Ce}_{0,50} \mathrm{Zr}_{0,50} \mathrm{O}_{2}$. A adsorção de etanol no suporte, à temperatura ambiente, produziu as bandas: $1062 \mathrm{~cm}^{-1}$ referente ao modo de vibração $\mathrm{v}(\mathrm{C}-\mathrm{O})$, atribuído à espécie etóxi na superfície do $\mathrm{Ce}_{0,50} \mathrm{Zr}_{0,50} \mathrm{O}_{2} ; 1322$ e $1386 \mathrm{~cm}^{-1}$ atribuídas ao modo de vibração $\delta_{\mathrm{s}}\left(\mathrm{CH}_{3}, \mathrm{CH}_{2}\right) ; 1481 \mathrm{~cm}^{-1}$ correspondente ao modo vibracional $\delta_{\text {as }}\left(\mathrm{CH}_{3}, \mathrm{CH}_{2}\right) ; 1585 \mathrm{~cm}^{-1}$ atribuída a espécies acetato e as bandas em 2898 e $2976 \mathrm{~cm}^{-1}$, ao modo vibracional $v\left(\mathrm{CH}_{3}, \mathrm{CH}_{2}\right) .32$ Com o aumento de temperatura a $100{ }^{\circ} \mathrm{C}$ houve aumento da banda referente às espécies etóxi. A $200{ }^{\circ} \mathrm{C}$ ocorreu aparecimento da banda associada à espécie acetaldeído em $1716 \mathrm{~cm}^{-1}$, aumento da intensidade das bandas associadas às espécies acetato e diminuição da banda da espécie etóxi. Esta banda a $300{ }^{\circ} \mathrm{C}$ desapareceu totalmente, surgindo bandas de $\mathrm{CO}_{2}$ na forma gasosa. No suporte $\mathrm{Ce}_{0,50} \mathrm{Zr}_{0,50} \mathrm{O}_{2}$, sua grande capacidade de troca de oxigênio favoreceu a formação de espécies acetato a partir da temperatura ambiente, que levou à produção de $\mathrm{CO}_{2}$, à $300{ }^{\circ} \mathrm{C} .{ }^{28}$

$\mathrm{O}$ catalisador $1,5 \% \mathrm{Rh} / \mathrm{Ce}_{0,50} \mathrm{Zr}_{0,50} \mathrm{O}_{2}$ obteve uma melhor atividade para a reação de desidrogenação do etanol a acetaldeído. O catalisador $1,5 \% \mathrm{Rh} / \mathrm{Ce}_{0,50} \mathrm{Zr}_{0,50} \mathrm{O}_{2}$, à temperatura ambiente, apresentou maior formação de espécies acetato do que no seu suporte. Sendo assim, as taxas das reações de oxidação das espécies etóxi a acetato e de sua decomposição a $\mathrm{CO}_{2}$ são promovidas no catalisador $1,5 \%$ $\mathrm{Rh} / \mathrm{Ce}_{0,50} \mathrm{Zr}_{0,50} \mathrm{O}_{2}$.

Para os outros suportes $\mathrm{Ce}_{0,75} \mathrm{Zr}_{0,25} \mathrm{O}_{2} \mathrm{e} \mathrm{Ce}_{0,25} \mathrm{Zr}_{0,75} \mathrm{O}_{2}$ foram obtidos os mesmos resultados, concluindo-se que a atividade dos respectivos catalisadores foi melhor do que a de seus suportes, devido à presença da fase metálica.

Dentre os suportes, o que apresentou a melhor atividade foi o $\mathrm{CeO}_{2}$, pois de acordo com a literatura, pelo fato deste suporte ter uma maior capacidade de troca de oxigênio favorecerá maior produção de espécies acetato, que levarão à produção de metano e $\mathrm{CO}_{2}{ }^{28}$ Então, as taxas da reação de oxidação das espécies etóxi a acetato e de sua decomposição a $\mathrm{CO}_{2}$ são promovidas no suporte $\mathrm{CeO}_{2}$.

\section{CONCLUSÕES}

Através de estudos de DRIFTS da reação de oxidação parcial do etanol em catalisadores de ródio suportados foi demonstrado um mecanismo de adsorção de etanol diferente dos outros metais comumente utilizados para oxidação parcial de etanol. Espécies etóxi podem perder um hidrogênio do grupo terminal metil e, dessa forma, serem adsorvidas em uma configuração cíclica para a superfície do metal através de um intermediário oximetaciclo. Os catalisadores contendo $\mathrm{CeO}_{2}$ no suporte se mostraram mais ativos para as reações de oxidação das espécies etóxi a acetato e de sua decomposição a $\mathrm{CO}_{2}$, devido às suas propriedades de armazenamento de oxigênio.

\section{MATERIAL SUPLEMENTAR}

O material suplementar, disponível em http://quimicanova.sbq. org.br, em arquivo PDF e com acesso livre apresenta as Figuras 1S (a-b) com os espectros de DRIFTS obtidos sob a mistura reacional etanol $/ \mathrm{O}_{2}$ a diferentes temperaturas no suporte $\gamma-\mathrm{Al}_{2} \mathrm{O}_{3} ; 2 \mathrm{~S}$ (a-b) com os espectros de DRIFTS obtidos sob a mistura reacional etanol/ $\mathrm{O}_{2}$ a diferentes temperaturas no suporte $\mathrm{CeO}_{2}$ e a $3 \mathrm{~S}$ mostrando os espectros de DRIFTS obtidos sob a mistura reacional etanol $/ \mathrm{O}_{2}$ a diferentes temperaturas no suporte $\mathrm{Ce}_{0,50} \mathrm{Zr}_{0,50} \mathrm{O}_{2}$.

\section{AGRADECIMENTOS}

A o apoio financeiro do CNPq e do MCT.

\section{REFERÊNCIAS}

1. Brammer, J. G.; Lauer, M.; Bridgwater, A. V.; Energy Policy 2006, 34, 2871.

2. Xuan, J.; Leung, M. K. H.; Leung, D. Y. C.; Ni, M.; Renewable Sustainable Energy Rev. 2009, 13, 1301.

3. Barbaro, P.; Bianchini, C.; Catalysis for Sustainable Energy Production, Wiley-VCH: Weinheim, 2009.

4. Fatsikostas A. N.; Verykios, X. E.; J. Catal. 2004, 225, 439.

5. Lisboa, J. S.; Terra, L. E.; Silva, P. R. J.; Saitovitch, H.; Passos, F. B.; Fuel Process. Technol. 2011, 92, 2075.

6. Tian, Z.; Dewaele, O.; Marin, G. B.; Catal. Lett. 1999, 57, 9.

7. Bozo, C.; Guilhaume, N.; Garbowski, E.; Primet, M.; Catal. Today 2000, 59,33 .

8. Dong, W. S.; Roh, H. S.; Jun, K. W.; Park, S. E.; Oh, Y. S.; Appl. Catal., A 2002, 226, 63 .

9. Vidal, H.; Kaspar, J.; Pijolat, M.; Colon, G.; Bernal, S.; Cordón, A.; Perrichon, V.; Fally, F.; Appl. Catal. 2001, 30, 75.

10. Yao, H. C.; Japar, S.; Shelef, M.; J. Catal. 1977, 50, 407; Hwang, C-P.; Yeh, C-T.; Zhu, Q.; Catal. Today 1999, 51, 93.

11. Diagne, C.; Idriss, H.; Kiennemann, A.; Catal. Commun. 2002, 3, 565.

12. Eriksson, S.; Nilsson, M.; Boutonnet, M.; Jaras, S.; Catal. Today 2005, $100,447$.

13. Fornasiero, P.; Di Monte, R.; Ranga Rao, G.; Kaspar, J.; Meriani, S.; Trovarelli, A.; Graziani, M.; J. Catal. 1995, 151, 168.

14. Fornasiero, P.; Kaspar, J.; Graziani, M.; Appl. Catal., B 1999, 22, L11.

15. Silva, A. M.; Costa, L. O. O.; Barandas, A. P. M. G.; Borges, L. E. P.; Mattos, L. V.; Noronha, F. B.; Catal. Today 2008, 133, 755.

16. Mavrikakis, M.; Barteau, M.A.; J. Mol. Catal. A: Chem. 1998, 131, 135.

17. Shekhar, R.; Barteau, M. A.; Plank, R. V.; Vohs, J. M; J. Phys. Chem. B 1997, 101, 7939.

18. Idriss, H.; Diagne, C.; Hindermann, J. P.; Kiennemann, A.; Barteau, M. A.; J. Catal. 1995, 155, 219.

19. Zhao, H.; Kim, J.; Koel, B. E.; Surf. Sci. 2003, 538, 147.

20. Gates, S. M.; Russel Jr., J. N.; Yates, J. T.; Surf. Sci. 1986, 171, 111.

21. Gursahani, K. I.; Alcala', R.; Cortright, R. D.; Dumesic, J. A.; Appl. Catal., A 2001, 222, 369.

22. Passos, F. B.; Schmal, M.; Frety, R.; Catal. Lett. 1992, 14, 57.

23. Menacherry, P. V.; Haller, G. L.; J. Catal. 1998, 177, 175.

24. Rachmady, W.; Vannice, M. A.; J. Catal. 2002, 207, 317.

25. Sheng, P. Y.; Yee, A.; Bowmaker, G. A.; Idriss, H.; J. Catal. 2002, 208, 393.

26. Idriss, H.; Seebauer, E. G.; J. Mol. Catal. A: Chem. 2000, 152, 201.

27. Yee, A.; Morrison, S. J.; Idriss, H.; J. Catal 2000, 191, 30.

28. Mattos, L. V.; Noronha, F. B.; J. Power Sources 2005, 145, 10.

29. Haurie, M.; Novak, A.; J. Chem. Phys. 1965, 62, 146.

30. Lima, S. M.; Da Cruz, I. O.; Jacobs, G.; Davis, B. H.; Mattos, L. V.; Noronha, F. B.; J. Catal. 2008, 257, 356.

31. Yee, A.; Morrison, S. J.; Idriss, H.; J. Catal. 1999, 186, 279.

32. Golay, S.; Doepper, R.; Renken, A.; Appl. Catal., A 1998, 172, 97. 